\title{
The effects of arthritis, mobility, and farm task on injury among older farmers
}

This article was published in the following Dove Press journal:

Nursing: Research and Reviews

9 May 2012

Number of times this article has been viewed

\section{Karen Heaton' \\ Andres Azuero' Jennan A Phillips' \\ Herretta Pickens' \\ Deborah Reed ${ }^{2}$}

'School of Nursing Birmingham, University of Alabama at Birmingham, AL, USA; ${ }^{2}$ College of Nursing, Lexington, KY, University of Kentucky, USA
Correspondence: Karen Heaton NB 534, 1530 3rd Ave S, Birmingham, AL 35180, USA

Tel +I 2059969467

Email kharnp@uab.edu
Abstract: The current study was conducted by performing secondary analysis of data drawn from a study of sustained work indicators of older farmers. The primary outcome variable was the reported occurrence or non-occurrence of injuries because of farm work in the past year. There were three explanatory variables of interest: (1) whether respondents reported ever having been diagnosed with arthritis/rheumatism by a medical doctor; (2) whether participants reported having mobility problems; and (3) a farm task injury risk index. Additional explanatory variables included the estimated number of days spent on farming activities in the past year, as well as demographic characteristics such as age, sex, and race. Institutional review board approvals were obtained for the original study prior to data collection, and for the current study prior to secondary analysis of data. Descriptive statistics were calculated for the outcome and explanatory variables. Initial multivariable longitudinal models for the occurrence of injuries were fitted with the explanatory variables. Odds ratios for the effects of interest were calculated using the final models. A longitudinal model was fitted using data in waves 1,3 , and 5 , with a farm task injury risk index as outcome variable and wave, sex, age, race, and estimated number of days spent on farming activities in the past year as explanatory variables for exploration of the relationship between the farm task injury risk index and these variables. In this group of older farmers, aging was protective for injury, and was associated with decreased farm task injury risk index. Arthritis/rheumatism was associated in our study with occurrence of injury because of farm work across all four waves. Our results indicated that farmers with mobility problems were twice as likely to experience injuries because of farm work compared to farmers with no mobility problems. Increased farm task injury risk index was associated with a $40 \%$ increase in odds for the occurrence of injury due to farm work. In this study of older farmers, the type of work, and not the amount of work was significantly associated with injury risk. Implications for future studies of farm injury include the need for nurse researchers and others to incorporate objective validated measures of mobility and health care provider diagnoses of arthritis, and arthritis type. Nurse researchers should proceed with ongoing evaluation of the farm task injury risk index to determine its validity, reliability, and usefulness as a predictor of farm injuries. In the practice setting, nurses may apply findings from this study to provide injury prevention teaching to older farmers and their families. For example, discussions of the more risky farm tasks, injury prevention strategies, and treatment modalities including those that promote improved mobility should be targeted to older farmers with arthritis and actual or potential mobility issues. Ultimately, these nursing research and practice efforts may lead to preservation of function, and decreased injury risk and severity among older farmers.

Keywords: aging, arthritis, mobility, farm injury

\section{Introduction}

The work of farmers is among the most deadly of all United States (US) job classifications. Year 2007 data indicated that farmers and ranchers experienced a tenfold 
increase in fatal injury rates (40\%) compared to that of all other workers (3.7\%). ${ }^{1}$ Not only is farm work dangerous; it is performed by groups of aging workers. Data from the National Agricultural Statistical Services (NASS) indicate that the mean age of US farmers is just over 57 years. ${ }^{2}$ The aging farmer is required to perform a broad range of tasks associated with variable injury risks during day-to-day farm operations. At the same time, age-related health issues may impact the aging farmer's ability to respond to hazards and avoid injury. The purpose of this paper is to explore the relationships between arthritis, mobility difficulties, and farm work exposures on injury in a group of older farmers.

\section{Review of the literature}

\section{Arthritis, aging, and mobility}

Arthritis, a term used to describe rheumatic diseases and conditions affecting joints, the tissues which surround the joint, and other connective tissue, is among the most prevalent chronic conditions in the US. Findings from the National Health Interview Survey for 2003-2005 indicated nearly $22 \%$ of the adult US population (46 million persons) had doctor-diagnosed arthritis. ${ }^{3}$ Arthritis prevalence increases markedly in both sexes beginning in the 45-54-year-old age group and continues to increase with each decade of life. ${ }^{4,5}$ The prevalence of doctor-diagnosed arthritis is expected to increase to an estimated 67 million (25\%) adults by the year 2030, due in part to the aging of the US population. ${ }^{3}$

Osteoarthritis (OA), the most common form of arthritis, affects 27 million US adults and is characterized by a gradual degenerative process accompanied by low-grade joint inflammation. ${ }^{6}$ This disorder may be classified as either primary OA, an idiopathic condition that developed in previously undamaged joints, ${ }^{7}$ or secondary OA, joint damage in response to physical stress such as in joint trauma, malalignment, or metabolic disorders. ${ }^{8}$ While a definitive cause for primary $\mathrm{OA}$ is unclear, its pathogenesis can be attributed to biomechanical stresses affecting the cartilage and subchondral bone, biochemical changes in the cartilage and synovial membrane, and genetic factors, all of which progressively worsen with age. ${ }^{9}$ Research points to an increased risk of $\mathrm{OA}$ and its associated disability and economic burden with increased age. ${ }^{10-14}$ Arthritis continues to be the most common cause of disability among adults with over 8.5 million US adults reporting an arthritis-related disability. ${ }^{15}$ Of over 4 million people with doctor-diagnosed arthritis, over 40\% (19 million) reported some limitations in their usual activities due to their arthritis. Almost 8 million adults reported functional limitations which interfered with their ability to stoop bend or kneel, and arthritis affected another 6 million persons' ability to walk a quarter mile. ${ }^{16}$ Arthritis predicted limitations in abilities which either remained stable or gradually increased in disability over time.

\section{Arthritis and injury in farmers}

Farmers experience an increased risk for the development of OA of the hip and knee, compared to workers in other job classifications. ${ }^{17,18}$ Awkward work positions, heavy lifting, ${ }^{19}$ repetitive bending, forceful work, ${ }^{20}$ and kneeling ${ }^{21}$ are common risk factors associated with the development of OA in farmers. Prolonged exposure to vibration from tractor-driving has also been identified as a risk factor for hip OA and subsequent total hip replacement in farmers. ${ }^{18}$

Arthritis is associated with injury in farmers. In a study of older Canadian farmers who sustained injuries $(n=282)$; those with OA were 1.5 times more likely to be injured, compared to farmers without the diagnosis of OA (odds ratio $[\mathrm{OR}]=1.57$; 95\% confidence interval [ $95 \% \mathrm{CI}]: 1.15-2.14){ }^{22}$ Sprince and colleagues promulgated the most extensive descriptions of the relationships between arthritis and specific injuries among Iowa farmers in a series of case-control studies using data from the Agricultural Health Study. Findings from these studies indicated that arthritis was significantly associated with falls $(\mathrm{OR}=2.60 ; 95 \% \mathrm{CI}: 1.49-4.52),{ }^{23}$ back injury $(\mathrm{OR}=2.30 ; 95 \% \mathrm{CI}=1.02-5.16) ;{ }^{24}$ and livestock-related injury $(\mathrm{OR}=3.00 ; 95 \% \mathrm{CI}=1.70-5.20) .^{25}$

\section{Farm tasks and injury}

While many potentially hazardous tasks are performed by farmers, a few tasks are consistently associated with injury. Reports within the past 10 years indicated that livestock or animal handling was associated with the highest numbers of severe farm injuries among New York farmers $(n=1706){ }^{26}$ high injury rates among female and male Colorado farmers $(n=760) ;{ }^{27}$ and accounted for $17 \%(n=44)$ of injuries among male Australian farmers. ${ }^{28}$ Farm maintenance/machinery repair was associated with almost a quarter of severe injuries among New York farmers ${ }^{26}$ and with the highest farm taskrelated injury rate per 100,000 hours worked among male Colorado farmers. ${ }^{27}$ Other important tasks associated with injury in these adult cohorts included fieldwork and crop production, and transportation. ${ }^{26-28}$

\section{Summary}

There are clear linkages between aging and arthritis, arthritis and mobility problems, and arthritis and injury. Also, the literature suggests that certain farm tasks are associated with 
higher risks of injury among farmers. However, none of the previous studies of farmers and injury have examined the relationships between arthritis, mobility, farm task risk, and injury. The purpose of this study is to explore those relationships among an older cohort of farmers.

\section{Methods}

\section{Research design and sample}

The current study was conducted by performing secondary analysis of data drawn from the study of sustained work indicators of older farmers, and was approved by the University of Alabama at Birmingham Institutional Review Board. The original observational study used a longitudinal approach. After approval for the original study was granted by the University of Kentucky Institutional Review Board, data were collected beginning in September of 2002, in five seasonally spaced waves of telephoned or mailed surveys, depending upon participant preference. The last wave of surveys was collected during April and May of 2006. First-wave respondents from 907 households included 1419 individuals aged 50 years and over. Survey response rates decreased for each wave with 1118 respondents (768 households), 990 respondents (684 households), 959 (665 households), and 597 (597 households) for waves 2, 3, 4, and 5, respectively. For wave 5 only one survey per household was requested. Data from all five waves were collected consistently from 479 households (52.8\%) and from 432 individuals (30.3\%). The statistical techniques used for the analyses in this study allow use of all available data at each wave; therefore the sample size varies according to each wave. Analyses of all available data are preferred to analyses of "completers" (ie, those who responded to all five waves), as the analyses for completers make very inefficient use of the available data, and if the completers are not a random sample from the target population, the analyses may produce biased population parameter estimates. ${ }^{29}$ For the analyses in this study, a respondent's data were included only for waves in which the respondent reported performing farm work.

\section{Study variables}

The primary outcome variable was the reported occurrence or nonoccurrence of injuries because of farm work in the past year. This binary outcome was calculated as a composite from six survey items that asked respondents if during the past year (or since the last survey for waves 2-5) they had experienced specifically as a consequence of farm work, any of the following: (1) cuts that required stitches, (2) reactions from use of chemicals, (3) burns, (4) broken bones, (5) loss of fingers or other extremities, or (6) other types of injuries due to farm work such as sprains or strains. Occurrence of injures was defined as having experienced at least one of these six types injuries due to farm work.

There were three explanatory variables of interest: (1) whether respondents reported ever having been diagnosed with arthritis/rheumatism by a medical doctor; (2) whether participants reported having mobility problems; and (3) a farm task injury risk index. The mobility problems indicator variable was calculated as a composite from nine survey items that asked respondents if they had difficulty (1) walking a quarter mile, (2) walking ten steps without rest, (3) standing or being on their feet for 2 hours, (4) sitting for 2 hours, (5) stooping, crouching, or kneeling, (6) reaching up over their head, (7) reaching out, (8) using their fingers to pick up a coin, or (9) lifting or carrying at least $10 \mathrm{lbs} .{ }^{30}$ The presence of mobility problems was defined as having responded affirmatively to at least one of these nine survey items. The farm task injury risk index was calculated as a weighted sum of 19 items that asked participants if during the past year they had performed any of the 19 farming tasks shown in Table 1. Affirmative answers to each of these 19 items were coded as 1 and negative answers were coded as 0 . The risk index was calculated as the sum of the answers multiplied by their respective risk ranking. The risk rankings range from 1 (lower risk of injury) to 4 (higher risk of injury). These rankings were based on a review of the farm injury literature. ${ }^{31-34}$ Thus, farm task injury risk index ranges from 0 to 49. Diagnosis of arthritis/rheumatism by a doctor

Table I Farming tasks and risk rankings used to calculate the farm task injury risk index

\begin{tabular}{ll}
\hline Farming task performed in the past year & Risk ranking* \\
\hline I. Mow fields & 3 \\
2. Till ground (plow, disc) & 3 \\
3. Apply pesticides, herbicides or insecticides & 2 \\
4. Bale hay or straw & 4 \\
5. Chop silage & 4 \\
6. Plant crops & 2 \\
7. Operate a combine/cotton picker & 3 \\
8. Hand-harvested crop (ie, tobacco, row crops) & 4 \\
9. Transport crops & I \\
I0. Feed animals & 2 \\
II. Milk animals & 2 \\
I2. Castrate animals & 4 \\
I3. Other veterinarian work & 3 \\
I4. Herd animals & 3 \\
I5. Transport animals & I \\
16. Climbed higher than 8 feet & 3 \\
I7. Repair farm equipment/tools & 2 \\
I8. Run farm errands & I \\
19. Operated equipment on highways & 2 \\
\hline Note:Rang: I lower risk of injury) -4 (higher risk of injur).
\end{tabular}

Note: *Range: I (lower risk of injury) - 4 (higher risk of injury). 
was not asked at wave 2 . Therefore, wave- 2 respondents who reported arthritis/rheumatism diagnosis at wave 1 or intake of arthritis/rheumatism medications at wave 2 were coded as having arthritis/rheumatism conditions at wave 2 . Items related to mobility were collected on waves 2 and 4, therefore the mobility problems indicator variable was calculated for those two waves only. The 19 items used to calculate the farm task injury risk index were collected in waves 1,3 , and 5; therefore the index was available only for these three waves.

Additional explanatory variables included the estimated number of days spent on farming activities in the past year, as well as demographic characteristics such as age, sex, and race, which were examined as possible confounders for the relationship between injuries and the three explanatory variables of interest.

Only at wave 4 did the original survey include an item asking about the number of days spent on farm work in the past year. However, all waves included an item that asked about the reported number of hours spent on farm work in the past week. At wave 4, a simple regression model for the number of days spent on farm work in the past year as a function of the number of hours spent on farm work in the past week resulted in a coefficient of determination $\mathrm{R}^{2}$ of $0.59(P<0.0001)$, which indicated a significant association between the two items. Further, visual inspection of the scatter plot between the two items indicated a curvilinear relationship. Therefore, a polynomial regression (including squared and cubic terms) with number of hours spent on farm work in the past week as explanatory variable was fitted to estimate the number of days of farm work in the past year. The polynomial regression model resulted in better fit than the simple regression model, with $\mathrm{R}^{2}$ of $0.73(P<0.0001)$. Thus, for waves $1,2,3$, and 5 the number of days spent on farm work in the past year was estimated using the polynomial regression equation developed for wave 4, with the number of hours spent on farm work in the past week as independent variable.

Because the primary outcome of this study is the occurrence of injuries due to farm work, for the analyses in this study, a respondent's data were included only for waves in which the respondent's estimate of days spent on farm work in the past year was greater than zero (ie, the respondent performed farm work in the past year and thus was at risk of injury).

\section{Analyses}

Descriptive statistics were calculated for the outcome and explanatory variables. The primary analyses examined the relationship between the main outcome variable, occurrence of injuries, and the explanatory variables.

For data in waves 1, 3, and 5, an initial multivariable longitudinal model for the occurrence of injuries was fitted with the following explanatory variables: wave number, age, sex, race, diagnosis of arthritis/rheumatism, farm task injury risk index, estimated number of days spent on farming activities in the past year, and three interactions between wave number and the following: arthritis/rheumatism diagnosis, farm task injury risk index, and estimated number of days spent on farming activities in the past year. The purpose of the interactions was to determine if the effects on the odds of injury of diagnosis of arthritis/rheumatism, farm task injury risk index, and estimated number of days spent on farming activities in the past year changed across waves. The initial model was depurated using a backward selection algorithm and only statistically significant predictor variables were retained in the final model. Odds ratios for the effects of interest were calculated using the final model.

For the data in waves 2 and 4, a multivariable longitudinal model for the occurrence of injuries was fitted with the following explanatory variables: wave number, age, sex, race, mobility problems indicator, arthritis/rheumatism indicator, estimated number of days spent on farming activities in the past year, and three interactions between wave number and the following: mobility problems indicator, arthritis/ rheumatism indicator, and estimated number of days spent on farming activities in the past year. The initial model was depurated using a backward selection algorithm and only statistically significant predictor variables were retained in

Table 2 Number of respondents and reported injuries due to farm by wave

\begin{tabular}{|c|c|c|c|c|c|}
\hline \multirow{2}{*}{$\begin{array}{l}\text { Occurrence of injuries because of farm } \\
\text { work in the past } 12 \text { months }\end{array}$} & \multicolumn{5}{|l|}{ Wave } \\
\hline & $I(n=92 I)$ & $2(n=760)$ & $3(n=735)$ & $4(n=755)$ & $5(n=433)$ \\
\hline I. Cuts that required stitches, $\mathrm{n}(\%)$ & $49(5.33)$ & $34(4.48)$ & $34(4.63)$ & $27(3.58)$ & $20(4.62)$ \\
\hline 2. Reactions from use of chemicals, $n(\%)$ & $9(0.98)$ & II (I.45) & $5(0.69)$ & $2(0.27)$ & $2(0.47)$ \\
\hline 3. Burns, n (\%) & $43(4.67)$ & $6(0.79)$ & $12(1.64)$ & $5(0.67)$ & $9(2.08)$ \\
\hline 4. Broken bones, $n(\%)$ & $21(2.29)$ & $17(2.24)$ & $7(0.96)$ & $26(3.45)$ & $15(3.47)$ \\
\hline 5. Loss of fingers or other extremities, $n(\%)$ & $2(0.22)$ & $I(0.14)$ & I (0.14) & $2(0.27)$ & $0(0)$ \\
\hline 6. Other types of injuries, $n$ (\%) & $134(14.55)$ & $105(13.82)$ & $90(12.25)$ & $93(12.32)$ & $46(10.63)$ \\
\hline Occurrence of at least one injury, $n$ (\%) & $219(23.78)$ & 154 (20.27) & $13 \mid(17.83)$ & $137(18.15)$ & $78(18.02)$ \\
\hline
\end{tabular}


the final model. Odds ratios for the effects of interest were calculated using the final model.

The longitudinal models for the occurrence of injuries were fitted using generalized linear mixed models. Because the outcome was binary, the logit transformation was used. Random effects for individual and household were fitted to account for statistical dependency among repeated observations on the same participant and among participants in the same household. Linear and generalized linear mixed models are fitted by maximum likelihood methods and therefore produce unbiased model parameter estimates in the presence of missing data that can be assumed missing at random. ${ }^{35}$ All analyses were conducted using SAS software (v. 9.2; SAS Institute, Cary, NC). The longitudinal models for occurrence of injuries were fitted using the GLIMMIX procedure in SAS. Statistical significance was set at $P=0.05$.

Additional analyses were conducted for the farm task injury risk index. A longitudinal model was fitted using data in waves 1,3 , and 5 , with farm task injury risk index as outcome variable and wave, sex, age, race, and estimated number of days spent on farming activities in the past year as explanatory variables for exploration of the relationship between the farm task injury risk index and these variables. Random effects for individual and household were fitted. Only significant predictor variables were retained in the final model. These models were fitted using the MIXED procedure in SAS.

\section{Results}

\section{Sample characteristics}

At wave 1, the sample consisted of 1419 individual survey respondents in 907 households. Participant ages ranged from 40 to 90 years, with an average of 65.3 (standard deviation $[\mathrm{SD}]=8.43)$. Men comprised 50.7\% $(n=719)$ of the sample. Participants reported an average of $12.1(\mathrm{SD}=3.1)$ years of formal education. About 78.5\% $(n=1108)$ were white, and $20 \%(n=286)$ were African American. The majority of participants $(n=1249 ; 88.6 \%$ ) owned their farm land. The average number of years farming their land was 31.7 years ( $\mathrm{SD}=14.2$ years). About $78 \%(n=1103)$ reported doing farm work before the age of 18 years. Participants' average reported percentage of household income from farming was estimated at $28.2 \%(\mathrm{SD}=28.9 \%)$. Table 2 describes the number of participants who experienced various farm-work-related injuries over all waves of the study. The incidence of at least one injury because of farm work for a 12-month period was estimated at $19.95 \%$. Descriptive statistics for reported injuries, diagnosis of arthritis/rheumatism, mobility problems, and farm injury risk index by wave are summarized in Table 3 .

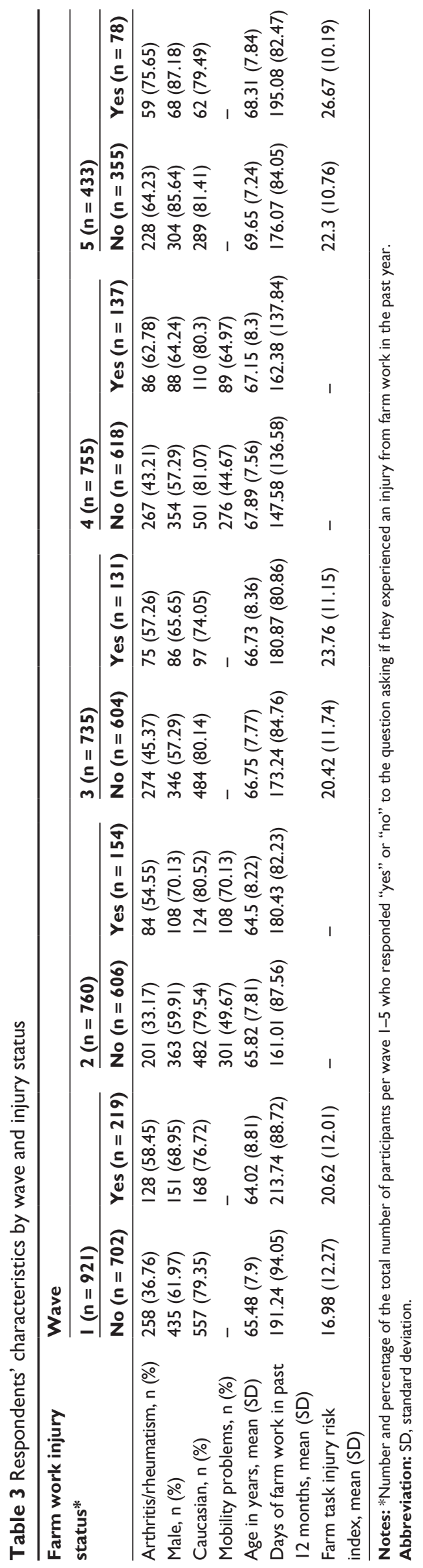


Table 4 Longitudinal models for the occurrence of injuries because of farm work using data from waves I, 3, and 4

\begin{tabular}{|c|c|c|c|c|c|}
\hline \multirow[t]{2}{*}{ Predictors } & \multicolumn{2}{|l|}{ Initial model } & \multicolumn{3}{|l|}{ Final model } \\
\hline & Estimate (SE) & $P$ & Estimate (SE) & $\boldsymbol{P}$ & Odds ratio $(95 \% \mathrm{Cl})$ \\
\hline Intercept & $-1.574(0.69)$ & 0.0226 & $-1.402(0.565)$ & 0.0131 & \\
\hline Wave I & $0.723(0.49)$ & 0.1401 & $0.602(0.15)$ & $<0.0001$ & I.824 (I.36I, 2.445) \\
\hline Wave 3 & $0.596(0.523)$ & 0.2542 & $0.139(0.154)$ & 0.3658 & I.I $49(0.85,1.553)$ \\
\hline Wave 5 (reference) & - & - & - & - & - \\
\hline Age & $-0.019(0.009)$ & 0.0189 & $-0.019(0.008)$ & 0.0154 & †0.856 (0.755, 0.97I) \\
\hline Male & $0.069(0.164)$ & 0.6749 & & & \\
\hline Caucasian & $-0.209(0.149)$ & 0.1588 & & & \\
\hline Arthritis/rheumatism & $0.55(0.284)$ & 0.0529 & $0.687(0.12)$ & $<0.0001$ & $1.988(1.57 I, 2.515)$ \\
\hline Farm task injury risk index & $0.035(0.015)$ & 0.0164 & $0.028(0.006)$ & $<0.0001$ & $\dagger 1.426(1.258,1.616)$ \\
\hline Days of farm work in past 12 months & $0.002(0.002)$ & 0.5594 & & & \\
\hline Arthritis/rheumatism wave $\times 1$ & $0.299(0.321)$ & 0.353 & & & \\
\hline Arthritis/rheumatism wave $\times 3$ & $-0.04 \mathrm{I}(0.342)$ & 0.9056 & & & \\
\hline Risk index $\times$ wave I & $-0.019(0.016)$ & 0.2567 & & & \\
\hline Risk index $\times$ wave 3 & $-0.003(0.018)$ & 0.8676 & & & \\
\hline Days of farm work $\times$ wave I & $0.001(0.003)$ & 0.8268 & & & \\
\hline Days of farm work $\times$ wave 3 & $-0.002(0.003)$ & 0.4122 & & & \\
\hline
\end{tabular}

Notes: ${ }^{\dagger}$ Odds ratio for a standard deviation (SD) increase (estimated SD for age $=8.24$; estimated SD for risk index $=12.67$ ). Abbreviations: $\mathrm{Cl}$, confidence interval; SE, standard error.

\section{Relationship between occurrence of injuries and explanatory variables}

The multivariable longitudinal model examining the relationship between the occurrence of injuries and wave, age, sex, race, diagnosis of arthritis/rheumatism, farm task injury risk index, and number of days of farm work, for waves 1,3 , and 5 , resulted in significant associations for wave, age, diagnosis of arthritis/rheumatism, and farm task injury risk index. The odds of injury were higher in wave 1 compared to waves 3 and 5. A decrease in the odds of injury was associated with an increase in age. Increases in the odds of injury were associated with an increase in the farm task risk injury index, as well as with reports of arthritis/rheumatism. Model details and adjusted odds ratios are presented in Table 4.

The multivariable longitudinal model examining the relationship between injuries and wave, age, sex, race, arthritis/rheumatism, mobility problems, and number of days of farm work, for waves 2 and 4, resulted in significant associations for age, sex, arthritis/rheumatism, and mobility problems. A decrease in the odds of injury was associated with an increase in age; the odds of injury were higher for males compared to females; and increases in the odds of injury were associated with reports of arthritis/rheumatism, as well as with reports of mobility problems. Model details and adjusted odds ratios are presented in Table 5.

The multivariable longitudinal model examining the relationship between farm task injury risk index and wave, sex, age, race, and number of days of farm work, for waves 1,3 , and 5 resulted in significant associations for all explanatory variables. The wave effect resulted from an overall lower average risk index at wave 1, compared to waves 3 or 5 . Across the three waves, men had greater average farm task injury risk index compared to women; increases in age were associated to decreases in the risk index; Caucasian respondents had an average farm injury risk greater than that of other ethnic groups combined; and increases in the number days of farm work in the past 12 months were associated with increases in the farm task injury risk index. Model details are presented in Table 6.

\section{Discussion}

This longitudinal, observational study explored the relationships between arthritis, mobility, farm work exposures, and injury among older farmers. Findings from this study support the work of previous authors, and add new information to the body of knowledge of older farmers and injury.

In this group of older farmers, aging was protective for injury, and was associated with decreased farm task injury risk index. This supports previous findings that increased injury risk is associated with younger age groups. ${ }^{21,25}$ Also, our findings suggest that, as farmers age, they disengage from more hazardous tasks, thus supporting the conclusions of Mariger et al. as related to a sample of Virginia farmers. ${ }^{36}$ It is important to note, however, that most of the injuries reported in this study were minor. The injury category labeled "other" primarily included such problems as sprains, strains, and bruises. It may be that because we did not capture severe or fatal injury data, we did not find the commonly reported association of aging with increased risk for severe and fatal farm injuries. . $^{32,37,38}$ 
Table 5 Longitudinal models for the occurrence of injuries because of farm work using data from waves 2 and 4

\begin{tabular}{|c|c|c|c|c|c|}
\hline \multirow[t]{2}{*}{ Predictors } & \multicolumn{2}{|l|}{ Initial model } & \multicolumn{3}{|l|}{ Final model } \\
\hline & Estimate (SE) & $P$ & Estimate (SE) & $P$ & Odds ratio $(95 \% \mathrm{CI})$ \\
\hline Intercept & $0.311(0.726)$ & 0.6687 & $0.584(0.676)$ & 0.3883 & \\
\hline Wave 2 & $-0.068(0.363)$ & 0.8528 & & & \\
\hline Wave 4 (reference) & - & - & & & \\
\hline Age & $-0.046(0.011)$ & $<0.0001$ & $-0.048(0.011)$ & $<0.0001$ & †0.685 $(0.58,0.81)$ \\
\hline Male & $0.525(0.181)$ & 0.0038 & $0.59(0.168)$ & 0.0004 & $1.804(1.299,2.505)$ \\
\hline Caucasian & $0.127(0.206)$ & 0.5383 & & & \\
\hline Arthritis/rheumatism & $0.645(0.218)$ & 0.0032 & $0.663(0.163)$ & $<0.0001$ & $1.94(1.409,2.67)$ \\
\hline Mobility problems & $0.771(0.222)$ & 0.0005 & $0.728(0.17)$ & $<0.0001$ & $2.071(1.485,2.887)$ \\
\hline Days of farm work in past 12 months & $0.001(0.001)$ & 0.6883 & & & \\
\hline Arthritis/rheumatism $\times$ wave 2 & $-0.009(0.307)$ & 0.9787 & & & \\
\hline Mobility problems $\times$ wave 2 & $-0.113(0.314)$ & 0.7209 & & & \\
\hline Days of farm work $\times$ wave 2 & $0.002(0.002)$ & 0.3647 & & & \\
\hline
\end{tabular}

Notes: ${ }^{\dagger}$ Odds ratio for a standard deviation (SD) increase (estimated SD for age $=8.32$ ).

Abbreviations: $\mathrm{Cl}$, confidence interval; SE, standard error.

Arthritis/rheumatism was associated in our study with occurrence of injury because of farm work across all four waves. This is consistent with the findings of Sprince et al. ${ }^{23-25}$ and Voaklander ${ }^{22}$ in their studies of injuries among farmers. While the study of severe farm injuries among New York farmers ${ }^{26}$ did not specifically identify arthritis or rheumatism as an injury risk factor, "joint trouble" was associated with an almost threefold risk of severe injury.

While other authors have concluded, post hoc, that mobility issues associated with arthritis may contribute to injury risk in older farmers, ${ }^{22,23,25}$ our study made a unique contribution by analyzing questions about mobility included in the original survey instrument. Our results indicate that farmers with mobility problems are twice as likely to experience injuries because of farm work compared to farmers with no mobility problems.

Along with the analysis of mobility problems, another innovative contribution of our study was the development and analysis of the farm task injury risk index. Increased farm task injury risk index was associated with a $40 \%$ increase in odds for the occurrence of injury due to farm work. Initially,

Table 6 Longitudinal model for the farm task injury risk index using data from waves I, 3 , and 5

\begin{tabular}{lll}
\hline Predictors & Estimate (SE) & $\boldsymbol{P}$ \\
\hline Intercept & $20.305(2.469)$ & $<0.000 \mathrm{I}$ \\
Wave I & $-5.004(0.537)$ & $<0.000 \mathrm{I}$ \\
Wave 3 & $-0.022(0.498)$ & 0.9653 \\
Wave 5 (reference) & - & - \\
Male & $\mathrm{II} .818(0.5 \mathrm{I})$ & $<0.000 \mathrm{I}$ \\
Age & $-0.205(0.033)$ & $<0.000 \mathrm{I}$ \\
Caucasian & $\mathrm{I} .335(0.639)$ & 0.0369 \\
Days of farm work in past I2 months & $0.037(0.003)$ & $<0.000 \mathrm{I}$ \\
\hline
\end{tabular}

Abbreviation: SE, standard error. we assumed that exposure to increased time spent doing farm work would be associated with increased risk for injury. Yet, while the variable days of farm work was associated with significantly increased farm task injury risk index, it was not retained in the models for occurrence of injuries because of farm work across waves 1-4. Therefore, in this study of older farmers, the type of work, and not the amount of work was significantly associated with injury risk.

Limitations to the study include recall bias due to the self-report nature of the original data collection effort. It is possible that, due to recall bias, participants provided inaccurate or inconsistent data over the course of the four study waves. However, this may have been tempered by the intentional timing of the survey waves to capture the seasonal peaks and ebbs of farm work exposure. Also, these data were drawn from a sample of older farmers in the southeastern US. Therefore, findings may not be generalizable to older farmers in different regions of the US who may experience different injury risks because of differences in crops, terrain, weather conditions, etc. Finally, we did not analyze in this study if or how mobility problems changed over time in the farmers who reported mobility problems. Assuming that mobility degrades over time, it may have added to our understanding of mobility and injury to explore the relationships between time, mobility, and injury.

In spite of these limitations, this study has added to the body of knowledge of how arthritis and mobility may be related to injury in older farmers. Future studies should include objective measures of mobility and diagnosis of arthritis validated by health care providers. Ongoing evaluation of the farm task injury risk index should be done to determine its validity, reliability, and usefulness as a predictor of farm injuries. Over the long term, these studies may inform the development of inter- 
ventions for arthritis and mobility that will preserve function, and decrease injury risk and severity among older farmers.

\section{Acknowledgment}

Funding for original data collection: Reed (PI), R01OH7534, National Institute for Occupational Safety and Health.

\section{Disclosure}

The authors report no conflicts of interest in this work.

\section{References}

1. US Bureau of Labor Statistics. Census of fatal occupational injuries charts 2010. [cited August 25, 2011]. Available from http://www.bls. gov/iif/oshwc/cfoi/cfch0009.pdf. Accessed October 31, 2011.

2. National Agricultural Statistical Service. 2007 Census of Agriculture: Demographics [cited October 21, 2009]. Available from http://www. agcensus.usda.gov/Publications/2007/Online_Highlights/Fact_Sheets/ demographics.pdf. Accessed October 31, 2011.

3. Hootman J, Helmick C. Projections of US prevalence of arthritis and associated activity limitations. Arthritis Rheum. 2006;54:226-229.

4. Theis K, Helmick C, Hootman J. Arthritis burden and impact are greater among US Women than men: Intervention opportunities. $J$ Womens Health (Larchmt). 2007;16:441-453.

5. Lawrence R, Felson D, Helmick C, et al; National Arthritis Data Workgroup. Estimates of the prevalence of arthritis and other rheumatic conditions in the United States. Part II. Arthritis Rheum. 2008;58:26-35.

6. Moskowitz R. The burden of osteoarthritis: clinical and quality-of-life issues. Am J Manag Care. 2009;15(8 Suppl):S223-S229.

7. Bierma-Zeinstra S, Koes B. Risk factors and prognostic factors of hip and knee osteoarthritis. Nat Clin Pract Rheumatol. 2007;3:78-85.

8. Sharma L, Kapoor D, Issa S. Epidemiology of osteoarthritis: An update. Curr Opin Rheumatol. 2006;18:147-156.

9. Godfrey J, Felson D. Toward optimal health: managing arthritis in women. An interview with David T. Felson by Jodi R. Godfrey. J Women Health. 2008;17:729-734.

10. Cozzensa da Silva M, Fassa A, Rodrigues Domingues M, Kriebel D. Knee pain and associated occupational factors. Cad Saude Publica. 2007;23:1763-1775.

11. Rodrigues M, Facchini L, Piccini R, et al. Use of primary care services by elderly people with chronic conditions. Rev Saude Publica. 2009;43:604-612.

12. Bitton R. The economic burden of osteoarthritis. Am J Manag Care. 2009;15(8 Suppl):S230-S235

13. Dunlop D, Manheim L, Yelin E, Song J, Chang R. The costs of arthritis. Arthritis Rheum. 2003;49:101-113.

14. Berger M, Doherty T. Sarcopenia: Prevalence, mechanisms, and functional consequences. Interdiscip Top Gerontol. 2010;37:94-114.

15. Hootman JM, Brault MW, Helmick CG, Theis KA, Armour BS. Prevalence and most common causes of disability among adults - United States, 2005. MMWR Morb Mortal Wkly Rep. 2009;58:421-426.

16. Hootman JM, Jeffrey Sacks JJ, Helmick CG. Prevalence of arthritis-attributable activity limitations among adults with doctordiagnosed arthritis, United States, 2002. Arthritis Rheum. 2004; 50(Suppl 9):5641.

Nursing: Research and Reviews

\section{Publish your work in this journal}

Nursing: Research and Reviews is an international, peer-reviewed, open access journal publishing original research, reports, reviews and commentaries on all aspects of nursing and patient care. These include patient education and counselling, ethics, management and organizational issues, diagnostics and prescribing, economics and
17. Davis $\mathrm{K}$, Kotowkis $\mathrm{S}$. Understanding the ergonomic risk for musculoskeletal disorders in the United States agricultural sector. $\mathrm{Am}$ J Ind Med. 2007;50:501-511.

18. Walker-Bone K, Palmer KT. Musculoskeletal disorders in farmers and farm workers. Occup Med (Lond). 2002;52:441-450.

19. Holmberg S, Thelin A, Thelin N. Is there an increased risk of knee osteoarthritis among farmers? A population-based case-control study. Int Arch Occup Environ Health. 2004;77:345-350.

20. Kirkhorn S, Greenlee R, Reeser J. The epidemiology of agriculture-related osteoarthritis and its impact on occupational disability. Wisconsin Med J. 2003;102:38-44.

21. Cooper C, McAlinidon T, Coggon D, Egger P, Dieppe P. Occupational activity and osteoarthritis of the knee. Ann Rheum Dis. 1994; 53:90-93.

22. Voaklander D, Kelly K, Rowe B, et al. Pain, medication, and injury in older farmers. Am J Ind Med. 2006;49:374-382.

23. Sprince N, Zwerling C, Lynch C, et al. Risk factors for falls among Iowa farmers: A case-control study nested in the Agricultural Health Study. Am J Ind Med. 2003;44:265-272.

24. Sprince N, Park H, Zwerling C, et al. Risk factors for low back injury among farmers in Iowa: A case-control study nested in the Agricultural Health Study. J Occup Environ Hyg. 2007;4:10-16.

25. Sprince N, Park H, Zwerling C, et al. Risk factors for animal-related injury among Iowa large-livestock farmers: A case-control study nested in the Agricultural Health Study. J Rural Health. 2003;19:165-173.

26. Hwang S, Gomex M, Stark A, et al. Severe farm injuries among New York farmers. Am J Ind Med. 2001;40:32-41.

27. Stallones L, Beseler C. Farm work practices and farm injuries in Colorado. Inj Prev. 2003;9:241-244.

28. Day L, Voaklander D, Sim M, et al. Risk factors for work related injury among male farmers. Occup Environ Med. 2009;66:312-318.

29. Mohlenbergs G, Kenward M. Missing Data in Clinical Studies. West Sussex, England: John Wiley \& Sons; 2007.

30. Centers for Disease Control/National Center for Health Statistics. 1994 supplement on aging (SOA II). Available from http://www.cdc.gov/ nchs/lsoa/soa2.htm. Accessed November 1, 2011.

31. Browning S, Truszczynska M, Reed D, McKnight R. Agricultural injuries among older Kentucky farmers: The Farm Family Health and Hazard Surveillance Study. Am J Ind Med. 1998;33:341-353.

32. Park T, Hartley J. Factors influencing the occurrence and severity of farm accidents: comparing work-related and nonwork-related events. J Agric Saf Health. 2002;8:83-94.

33. Myers J, Layne L, Marsh S. Injuries and fatalities to US farmers and farm workers 55 years and older. Am J Ind Med. 2009;52:185-194.

34. Rautianen R, Reynolds S. Mortality and morbidity in agriculture in the United States. J Agric Saf Health. 2002;8:259-276.

35. Fitzmaurice G. Missing data: Implications for analysis. Nutrition. 2008;24:200-202.

36. Mariger S, Grisso R, Perumpral J, et al. Virginial agricultural health and safety survey. J Agric Saf Health. 2009;15:37-47.

37. Centers for Disease Control and Prevention. Fatalities caused by cattlefour states, 2003-2008. MMWR. 2009;58:800-804.

38. Murphy C, McGuire C, O'Malley N, et al. Cow-related trauma: A 10 year review of injuries admitted to a single institution. Injury. $2010 ; 41: 548-550$.

resource management, health outcomes, and improving patient safety in all settings. The manuscript management system is completely online and includes a very quick and fair peer-review system. Visit http://www.dovepress.com/testimonials.php to read real quotes from published authors. 